\title{
Application of the european quality of life survey (EQLS) to the students of the university program for older adults of the University of Burgos (PIE)
}

\author{
Vanesa Baños-Martínez ${ }^{1 a}$ \\ ${ }^{1}$ Faculty of Education, Department of Science Education, University of Burgos, Spain
}

\begin{abstract}
This study presents a complete analysis of the quality of life of a group of older university students of the University of Burgos. The emphasis has been placed on the quality of life from a subjective point of view without forgetting that it involves multiple dimensions that range from health and public services to social exclusion. On the other hand, the relationship between education, quality of life and active aging has been sought and a strong and positive correlation has been found. We can state that university students, despite their age, have better quality of life than their citizens and, in this sense. We can conclude that the future of societies with strong aging processes of their population is to develop and expand active aging, either from the university or from other institutions. the oldest students over their own health is worse than that of the youngest.

Keywords: quality of life, university students, older adults
\end{abstract}

\section{Introduction}

The aging of the population is one of the most important challenges that faces contemporary Europe [13]. Predictions leave no room for doubt, by the middle of the twenty-first century, one in three citizens will be over 60 years old [6].

Because of that, it is worthwhile to encourage older people to take part in educational activities in their free time and thus put into practice the idea of lifelong learning. In this sense, University Programs for older adults represent a very praiseworthy effort to improve the quality of life (QoL) of the elderly and to cope with the increase of longevity and thus respond to the erroneous assumptions that associate aging with physical and/or intellectual decline [8].

Kuykendall, Tay \& Ng [12] argue that leisure activities promote subjective well-being in adulthood by their association with intrinsic motivations, perceived freedom and other psychological benefits. For example, a recent study concluded that leisure activities are

a Corresponding author: vbanos@ubu.es 
positively related to subjective well-being among older Chinese and that they may play a leading role in promoting healthy aging [20].

According to García [9], education in the elderly favours a better adjustment and greater life satisfaction and maintenance of optimal levels of QoL. Learning can benefit, at the health level, all the people regardless of their initial levels of mental and psychological well-being [1, 10, 19]. Education improves the QoL by increasing subjective well-being and personal and social knowledge which allows students to feel part of society [5].

Some studies confirm that about $75 \%$ of older people value their QoL as good or very good and the great majority of them adapt satisfactorily to the consequences of aging and refer to a high level of satisfaction with life [15]. Fernández-Ballesteros [7] states that older people score slightly above average on life satisfaction and slightly lower than average on happiness.

Other studies have concluded that women are generally less satisfied with their lives and are less happy than men at all ages and in old age $[11,18]$.

Perceived social support is important too [2] either through family relations or friendships, the conservation of them and interest in the social and institutional environment prevent the appearance of pathologies and the negative effects on health [14].

The economic situation has been related to well-being and the QoL in old age [17]. A macro study published in the medical journal "The Lancet" states that poverty and social inequality are highly detrimental to health. Stringhini, et al. [16] conclude that the socioeconomic level has a decisive influence on health.

In short, this research is important because it helps to strengthen the need for older people education, justifying the same in which the QoL of the students is maintained. On the other hand, it seeks to understand which dimensions are the most influential for the quality of life of the elderly, which can help managers and any educational or social agents related to University Programs for older adults to better adjust programming to give response to real needs.

The main objective of this research is to analyse the quality of life of the students of the University Program for older adults of the University of Burgos (PIE) in the headquarters of Burgos and Aranda de Duero.

\section{Method}

The applied sampling technique is a non-probabilistic sampling for convenience, since the group of subjects that includes the students of the University Program for older adults of the UBU in the headquarters of Burgos and Aranda de Duero has been selected given the accessibility and suitability of the same. It is divided naturally into groups, which in this research are identified as venues and for which these venues have been selected as the first to launch the Program at the UBU in 2002.

\subsection{Participants}

The choice of this methodology allows us to gather the opinion and assessment of the maximum number of students possible, maintain the anonymity of the respondents, favour the freedom of response and obtain varied, useful, reliable and valid information. The sample used consisted of 332 subjects, older than 50 years.

The questionnaire was answered anonymously and voluntarily by 332 students in October 2014, at the beginning of the academic year 2014/2015. Of the total, 119 people study in Aranda and 213 in Burgos. The sample is representative because it gathers answers of $97.65 \%$ of the total students, which are 340 people, the statistical formulation tells us that we have worked with an error rate of $1.09 \%$ and with a confidence interval of $99 \%$. 
A large sample has been chosen to be able to access also the small differences or weak relationships that may exist between the multiple variables.

\subsection{Instrument}

The selected technique to collect the data about QoL of the students of the University Program for older adults of the University of Burgos is the transversal design survey denominated EQLS 2012 of the European Foundation for the Improvement of the Living and Working Conditions (Eurofound) [3]. It is a survey of European citizens aimed at obtaining a perspective on the objective conditions of life and their perception of QoL. The work of the experts allows the questions contained in the questionnaire to capture the phenomena that are intended to capture in the real world (validity).

The EQLS has a four-year nature, dealing with several issues, such as employment, income, education, housing, family, health and reconciliation of work and family life. It is also interested in more subjective issues, such as the degree of happiness of the people, their satisfaction with their personal life and how they perceive the quality of their societies.

Among the different instruments reviewed for the realization of the present study, we have been interested in the EQLS 2012 because it is designed for the general population and not for the elderly specifically, so the results allow us to make broader comparisons. Also, our interest is that it measures both positive and negative aspects related to the QoL and reproduces the multidimensionality of the concept. It has been sought to know the behaviour of the instrument with a sample that is not the usual one. On the other hand, it is backed by the European institutions and is adapted to the Spanish population and duly validated.

For the research presented here, three questions were added to the questionnaire, which serve as classification data: place of residence, enrolment course and, for graduates only, number of years of permanence in the Program.

In a total of 66 issues, the EQLS 2012 addresses the following dimensions: employment and work-life balance, family and social life, health and public services, home and local environment, quality of society, social exclusion and community involvement, standard of living and deprivation and finally, subjective well-being.

The scales of answers are varied, because some of the questions are closed dichotomous, that is, they give only two answers: yes or no and, if appropriate, do not know/no answer; others are closed categorized because they present as answers a series of alternatives among which the respondent must choose an alternative and finally, there are also numerical questions in which the answer is asked to be expressed in number form.

\section{Findings}

In a first approximation to the various elements that make up subjective well-being, we face to the following aspects: being optimistic about the future, feeling that life is worthwhile, being free to decide how to live the life or not having time to do things that you enjoy. In this sense, as reflected in Figure 1, UBU students have the best results among all their peers, both Spanish and European, being the difference bigger with respect to the latter. On the other hand, if the comparison is made between the elderly of the UBU and the total sample of Spain, the university students value with $1 \%$ more their decision capacity; an $11 \%$ more of the students disagree with the affirmation "I rarely have time to do things that I really enjoy" and $82 \%$ emphatically affirm that their life is worth it. There is only a $3 \%$ difference in favour of the total Spanish sample about optimism about the future. The Spanish results, beyond the sample used in this research, are better than those of the Europeans in every single question collected here. Among the older people, we also 
observed that there are significant differences between the elderly of up to 64 years and those over 65 years old, the latter have slightly more negative results.

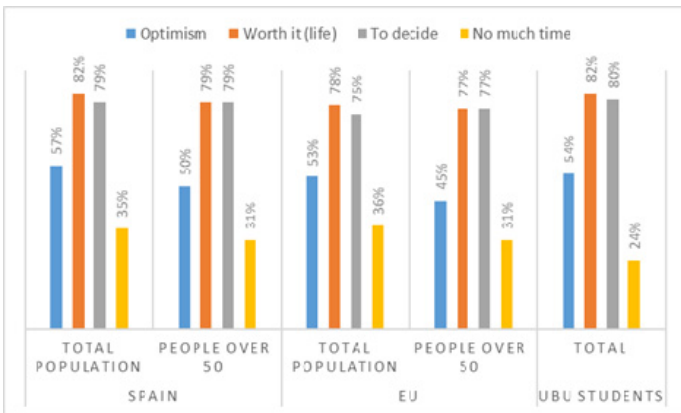

Fig.1. Comparison between Spain, EU and the UBU students on subjective well-being.

In relation to health as UBU students show a higher percentage of good health than the elderly of the Spanish sample (19\%) and European. So, they are placed very close to the total of the Spanish average. The differences are significant among those over 65 years of age and those aged between 50 and 64 years, with the latter having a $24 \%$ increase in positive responses (Figure 2). Health is one of the most important factors in the perception of the quality of life and it can be confirmed that UBU student who take part in a University Program for older adults present high levels.

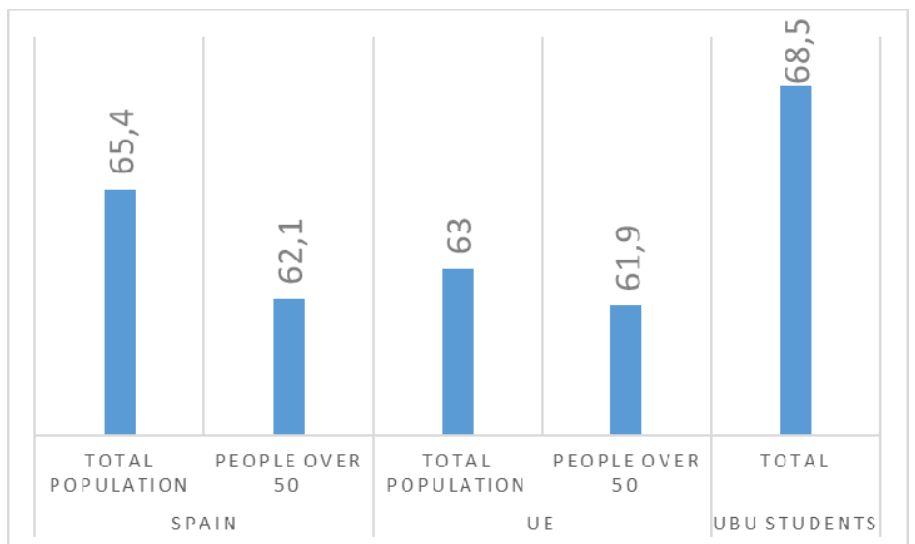

Fig. 2. Comparison between Spain, EU and the UBU students on health status considering the answers: "very good" or "good".

The analysis of the quality of the society leads us to the reflection that the UBU senior students have high levels of confidence in most people, more than the Spanish and European average and more than the elderly of the national sample. On the other hand, as shown in Figure 3, confidence in institutions is substantially lower for university graduates than for the rest of the population. This difference is clearly significant with respect to the legal system, where the PIE students are 6 tenths below and in relation to the local authorities, with about 1 point difference in favour of both, the general sample and the elderly of the global sample. In all aspects, those over 65 are more confident than those aged between 50 and 64 years. It seems that the younger ones are more critical of the institutions that represent, inform or protect them. There is scope for improvement in this sense and even more when we are aware that quality of society is an important aspect in the design of the overall model that has been made for the sample of the PIE. 


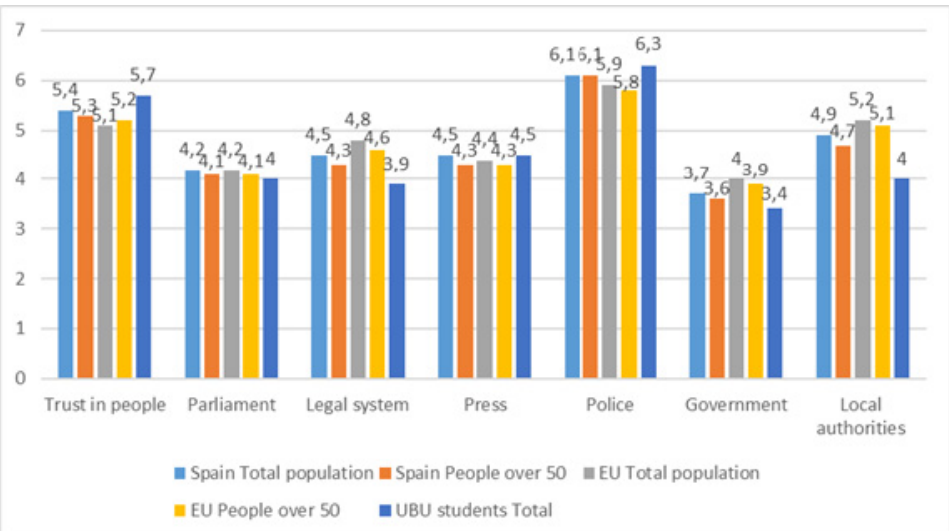

Fig. 3. Comparison between Spain, EU and the UBU students about the degree of confidence in different groups and institutions.

In relation to the perception of the quality about different services, university students are the ones that get a worse score, whether compared to the general sample or to those over 50 years of the total sample or even to the Europeans (Figure 4). Social housing, along with pensions or resources for the care of the sick or disabled, are the services that generate the most dissatisfaction.

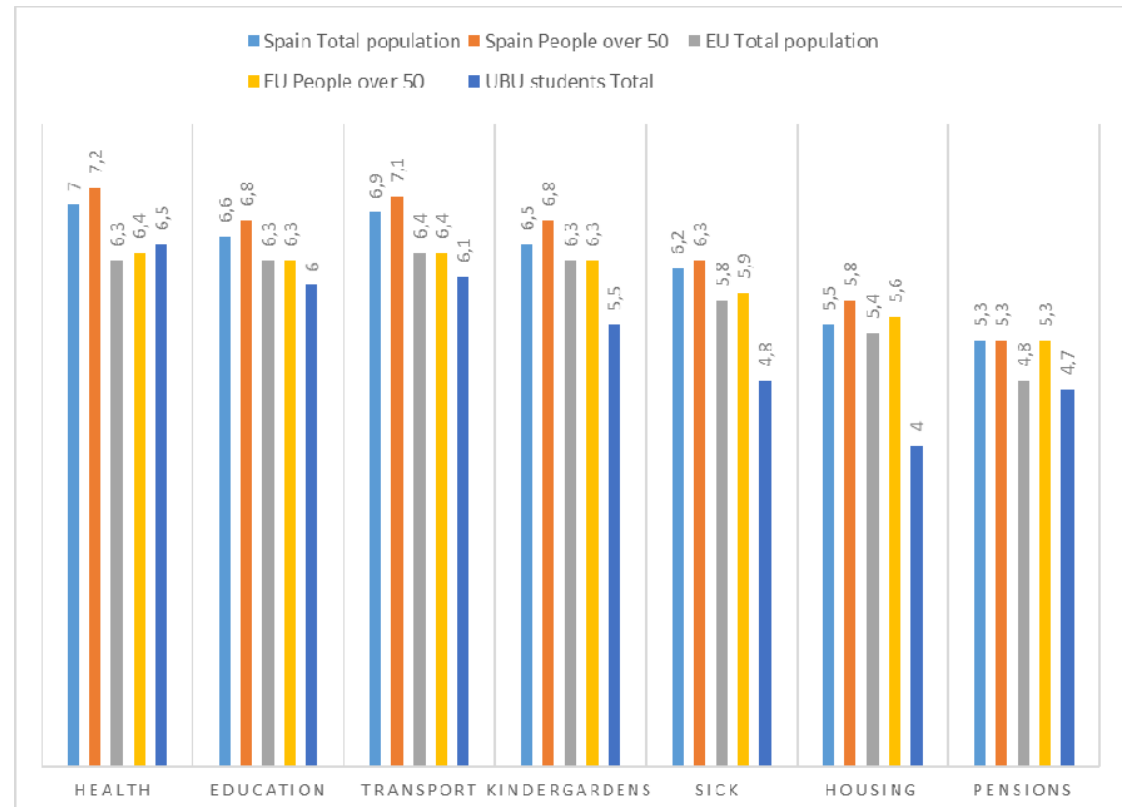

Fig. 4. Comparison between Spain, EU and the UBU students on the quality of different public services.

Broadly speaking, we can say that the UBU elderly students have good levels of health and mental well-being, with levels very similar to those of the general population. On the other hand, at the level of public services, although they do not find many factors that make it difficult, for example, medical visits, they consider that the quality of the most relevant public services in the country could be much higher. 


\section{Discussion and conclusion}

The participation of UBU students in training activities has been relevant to their subjective well-being, as it has been shown in previous studies [12, 20]. We corroborate that in this context there are opportunities for socialization, cognitive stimulation, personal growth and, occasionally, physical activity.

The PIE of the University of Burgos, as a leisure activity based on training, contributes to the integral development of students and this fact has positive consequences on the quality of life. The health benefits of participants, both physically and mentally, have also been verified. These results coincide with those presented by Argyle [1], Yanguas [19] and Hammond [10].

Our research presents points in common with the study of Fernández-Ballesteros [7], as in both cases the most economically favoured students are those who also have better health $[8,16,17]$ and that age influences the perception of health $[11,18]$.

In the case of the University of Burgos the elderly has strong social support, which although it positively influences their quality of life [2,14], is not decisive. Some of the students take care of their grandchildren occasionally and they do not feel stressed by their responsibility.

Overall, the results reinforce the idea that the UBU students from Burgos and Aranda de Duero have an active and satisfactory aging profile, away from the much-feared dependence, free of serious health problems, with good life satisfaction and high levels of happiness. These circumstances may not be a direct consequence of the PUMs, although we can affirm that university education contributes decisively to the maintenance of a good health status (physical and mental) and high levels of subjective well-being associated with self-esteem, self-confidence, to personal relationships or the sense of personal identity as members of the university community.

The University of Burgos is an example where it is shown that aging actively and with quality of life is possible in a university training environment that satisfies the needs of their students and provides them with the resources and tools necessary to achieve their personal development. Activity is the key to good aging and to achieve this is key to promote actions that focus on prevention, through the promotion of healthy living habits, and effective intervention programs focused on the person.

All the literature on active aging, lifelong learning and quality of life is a concrete reality in the University of Burgos elderly students.

\section{References}

1. M. Argyle The psychology of happiness. Routledge, (2013)

2. J. Buz, P. Mayoral, B. Bueno, J. L. Vega, Factores sociales del bienestar subjetivo en la vejez. Revista Española de Geriatría y Gerontología, 39(3), 23-29 (2004)

3. EQLS translated questionnaire. https://www.eurofound.europa.eu/surveys/europeanquality-of-life-surveys/european-quality-of-life-survey-2012/eqls-2012-questionnaire/eqls2012-questionnaire-translation

4. EQLS 2012 data. https://www.eurofound.europa.eu/es/surveys/datavisualisation/european-quality-of-life-survey-2012

5. P. Escuder-Mollon, R. Esteller-Curto, L. Ochoa, M. Bardus, Impact on senior learners' quality of life through lifelong learning. Procedia-Social and Behavioral Sciences, 131, 510-516 (2014)

6. European Comission. Comunicación sobre "Asociación Europea para la Innovación sobre un Envejecimiento Activo y Saludable" (COM (2012) 83 final). http://ec.europa.eu/health//sites/health/files/ageing/docs/com_2012_83_en.pdf 
7. R. Fernández-Ballesteros, Psicogerontoloía: perspectivas europeas para un mundo que envejece. Ediciones Pirámide., (2009)

8. M. Formosa, Lifelong learning in later life: The Universities of the Third Age. Lifelong Learning Institute Review, 5, 1-12, (2010)

9. A. J. García González, Variables psicosociales que inciden en la calidad de vida de los participantes en Programas Universitarios de Mayores. Sevilla: Servicio de Publicaciones., (2011)

10. C. Hammond, Impacts of lifelong learning upon emotional resilience, psychological and mental health: fieldwork evidence. Oxford Review of Education, 30(4), 551-568 (2004)

11. R. Inglehart, Gender, aging, and subjective well-being. International Journal of Comparative Sociology, 43(3-5), 391-408 (2002)

12. L. Kuykendall, L. Tay, V. Ng, Leisure engagement and subjective well-being: A meta-analysis. Psychological Bulletin, 141(2), 364-403 (2015)

13. J. Mackowicz, J. Wnek-Gozdek, "It's never too late to learn"-How does the Polish U3A change the quality of life for seniors? Educational Gerontology, 42(3), 186-197 (2016)

14. J. J. Maldonado Briegas, M. I. Fajardo Caldera, F. Vicente Castro, S. González Ballester, Adulto mayor y envejecimiento activo. Caso de éxito de una iniciativa emprendedora. International Journal of Developmental and Educational Psychology. Revista INFAD de Psicología, 1(2), 57-62 (2016)

15. M. Richart Martínez, J. Cabrero García, M.J. Cabañero Martínez, A. Reig Ferrer, Calidad de vida en la vejez. En Millán Calenti, J.C. Gerontología y geriatría: Valoración e intervención (pp 617-638). Madrid: Editorial Médica Panamericana, (2011)

16. S. Stringhini, et al. Socioeconomic status and the $25 \times 25$ risk factors as determinants of premature mortality: a multicohort study and meta-analysis of 1'7 million men and women. The Lancet. (2017)

17. A. Walker, Calidad de vida de las personas mayores. Análisis comparativo europeo. Revista Española de Geriatría y Gerontología, 39(3), 8-17 (2004)

18. Y. Yang, Social inequalities in happiness in the United States, 1972 to 2004: An ageperiod-cohort analysis. American sociological review, 73(2), 204-226 (2008)

19. J. Yanguas Lezaun, Análisis de la calidad de vida relacionada con la salud en la vejez desde una perspectiva multidimensional (No. 11002). Imserso. (2006).

20. W. Zhang, Q. Feng, J. Lacanienta, Z. Zhen, Leisure participation and subjective wellbeing: Exploring gender differences among elderly in Shanghai, China. Archives of Gerontology and Geriatrics, 69, 45-54 (2017) 